\title{
Coagulase testing compared with commercial kits for routinely identifying Staphylococcus aureus
}

\author{
A S Rossney, L F English, C T Keane
}

\begin{abstract}
Five commercial Staphylococcus aureus identification kits-Staphaurex (Wellcome), Staphylase (Oxoid), Staphyslide (bioMèrieux), Biostaph (Medlabs) and Bacto Latex (Difco)-were evaluated for the routine identification of $S$ aureus from primary plates in the routine microbiology laboratory. Comparison was made with two methods of tube coagulase testing and five slide methods for detecting clumping factor (slide coagulase testing). Performances were assessed for two groups of organisms, staphylococcal species alone and a combined staphylococcal and nonstaphylococcal species group. The effects of growth on selective media and storage of isolates at room temperature and $4^{\circ} \mathrm{C}$ were investigated. Selective media cannot be recommended, nor can storage of isolates before testing. Ranked according to efficiency value with the combined staphylococcal and non-staphylococcal species group, the kits and coagulase methods performed as follows (the figures in parentheses are the efficiency values for the staphylococcal group alone): tube coagulase reference method $100 \%(100 \%)$, tube coagulase SJH method 99\% (99\%), Staphaurex 94\% (97\%), Staphylase $93 \%(96 \%)$, slide coagulase method No 4 93\% (94\%), slide coagulase method No 5 93\% (93\%), Bacto Latex $92 \%$ $(95 \%)$, Staphyslide $92 \%(95 \%)$, and Biostaph $87 \%$ (91\%).

It is concluded that a commercial $S$ aureus identification kit should not replace tube coagulase testing for the routine identification of the organism from primary plates and that, even the kits with the best performances, have little advantage over a good slide coagulase test method.
\end{abstract}

\footnotetext{
Microbiology Department, St James's Hospital, Dublin A S Rossney L F English C T Keane

Correspondence to: A S Rossney, Microbiology Department, Central Pathology Laboratory, St James's Hospital, St James's Street, Dublin 8, Ireland. Accepted for publication Accepted for pub
19 October 1989
}

Tube coagulase testing is the accepted basis of Staphylococcus aureus identification. ${ }^{1-3}$ Detection of clumping factor by the so-called slide coagulase test provides a rapid result, but negative results should be confirmed by tube coagulase testing. ${ }^{3-6}$ Attempts to provide a rapid reliable $S$ aureus identification method have resulted in the development of several commercial kits using either passive haemagglutination, where sheep erythrocytes treated with formol saline are sensitised with human fibrinogen to detect clumping factor, or latex agglutination, where latex particles are coated with fibrinogen and immunoglobulin $G$ to detect clumping factor and protein $\mathrm{A} .{ }^{8}$

It is hoped that the routine use of such kits in place of tube coagulase testing would, in addition to producing rapid results, effect economies of time and material by eliminating unnecessary sensitivity testing on non-S aureus isolates. As tube coagulase testing is usually performed on strains subcultured from primary isolation plates, the chosen kit would have to be able to identify $S$ aureus from primary plates.

Before introducing a kit for the routine identification of $S$ aureus from primary plates, it is necessary to know how the kit performs with isolates grown on selective media because primary isolates may be available only on-for example, McConkey agar or cysteine lactose electrolyte deficient (CLED) agar. It is also necessary to know how storage of the isolate affects the kit's performance because, in many routine diagnostic laboratories, plates are stored over the weekend. The kit's ability to cope with non-staphylococcal species is important because in the routine diagnostic laboratory non-staphylococcal species may occasionally be inadvertently subcultured as staphylococcal species or the staphylococcal species may be mixed with a non-staphylococcal species.

To determine the feasibility of replacing tube coagulase testing with a commercial $S$ aureus identification kit in a large microbiology laboratory, five commercial $S$ aureus identification kits were evaluated. The kits were compared with a reference tube coagulase testing method, and the opportunity was taken to compare the modified tube coagulase test method used in this laboratory with the reference method. Because many different modifications of methods of detecting clumping factor by slide coagulase testing were used in various evaluations of commercial $S$ aureus identification kits, ${ }^{9-14}$ or the details of the methods used were unclear, ${ }^{81516}$ it seemed appropriate to include an evaluation of a number of slide coagulase test methods.

\section{Methods}

BACTERIAL STRAINS

Recent bench isolates grown on methicillin sensitivity test plates were subcultured on to Columbia blood agar plates and incubated for 18 hours at $35^{\circ} \mathrm{C}$ in air. Ninety three $S$ aureus strains resistant to gentamicin or methicillin, or both (GMRSA), stored on nutrient agar slopes 
were similarly subcultured. The GMRSA had been isolated over the previous eight months and only one isolate from each patient was included.

In total, 625 isolates, 582 staphylococcal species, and 43 non-staphylococcal species, were tested. The staphylococcal species comprised, in addition to the 93 GMRSA strains, $244 S$ aureus and 245 non- $S$ aureus staphylococci.

The non-staphylococcal species were included to assess the effect of unsuspected mixtures or the inadvertent presence of-for example, a Streptococcus species instead of a Staphylococcus species on the kits' performances. The non-staphylococcal species consisted of the following organisms: streptococci $(\mathrm{n}=31)$, Gram negative bacilli $(\mathrm{n}=11)$, and diphtheroids $(n=1)$.

The test strains were from clinical specimens, but isolates from specimens likely to yield a high proportion of coagulase negative staphylococci were excluded. The aim was to achieve a ratio of $S$ aureus: non- $S$ aureus staphylococci as close as possible to $50: 50$, not only to include sufficient $S$ aureus in the study but also because the routine coagulase test results during the trial period were $49 \%$ coagulase positive and $51 \%$ coagulase negative.

All isolates were tested for coagulase production by a reference tube method (Gillespie, 1943) ${ }^{4}$ and for deoxyribonuclease (DNase) production. ${ }^{17}$ All DNase producers were tested for the production of thermonuclease. ${ }^{18}$ Tube coagulase positive, thermonuclease positive isolates were deemed to be $S$ aureus. There was $100 \%$ correlation between tube coagulase positivity and thermonuclease production.

COMMERCIAL KITS

The kits evaluated were Staphaurex (Wellcome, England), Staphylase (Oxoid, England), Bacto Latex (Difco, USA), Biostaph (Medlabs, Ireland) and Staphyslide (bioMèrieux, France). All kits were used according to the manufacturers' instructions except insofar as some non-staphylococcal species were tested, contrary to the instructions for most kits. During the initial trial run, a problem was observed with the Biostaph kit. Known coagulase positive isolates failed to give positive results with this kit using the inoculum concentration recommended by the manufacturer. Positive results were obtained when the inoculum was increased. When using the Biostaph kit, in addition to the method recommended by the manufacturer, isolates were therefore also tested using heavy inocula.

After the initial study the three kits with the best performances were further evaluated to compare the effects of growing the test isolates on McConkey agar, diagnostic sensitivity test agar (DST), mannitol salt agar and CLED agar with growth on Columbia blood agar. Fresh isolates of 118 staphylococcal strains, 97 recent clinical isolates (57 $S$ aureus and 40 non- $S$ aureus staphylococci), 20 GMRSA, and $S$ aureus NCTC 6571 grown on Columbia blood agar at $35^{\circ} \mathrm{C}$ in air for 18 hours were subcultured on to each test medium and incubated at $35^{\circ} \mathrm{C}$ for 18 hours in air. Isolates on Columbia blood agar and on each test medium were tested by the three kits and retested after storage for 24,48 , and 72 hours. The effects of storage for 24,48 , and 72 hours at room temperature on Columbia blood agar were similarly determined. Because it is recommended that mannitol salt agar be incubated for 36 hours, ${ }^{19}$ isolates on mannitol salt agar after 18 hours' incubation were reincubated for 24 hours before testing.

\section{COAGULASE TESTING}

Tube coagulase test methods

1 Reference Method (Gillespie 1943) ${ }^{4}$ : Difco rabbit plasma $(0.1 \mathrm{ml} 1 / 10)$, diluted in $0.9 \%$ sodium chloride, with ethylenediaminetetraacetic acid (EDTA) anticoagulant, was added to $0.5 \mathrm{ml}$ overnight broth culture (Oxoid Nutrient Broth No 2). After incubation at $37^{\circ} \mathrm{C}$ in a waterbath, tests were examined for clot formation at one, three, and six hours. After overnight incubation at room temperature the final reading was made at 24 hours.

2 St James's Hospital ( $\mathrm{SJH}$ ) Coagulase Method: A single colony of overnight growth on Columbia blood agar was inoculated into 4 ml Oxoid Nutrient Broth No 2 and incubated for about two hours at $35^{\circ} \mathrm{C}$. Nine drops of broth culture were added to one drop of undiluted Standardised Normal Plasma (SNP $\mathrm{DADE}$ ) to which two drops of heparin per phial were added. After incubation at $35^{\circ} \mathrm{C}$ in an incubator, tests were read after about six and 24 hours' incubation.

Slide coagulase test methods

Five slide coagulase test methods, three standard textbook methods, and two modified methods were used.

1 Cowan and Steel": A single colony was emulsified with minimum spreading in a drop of distilled water on a microscope slide. The suspension was stirred with a straight wire that had been dipped in plasma (Rabbit EDTA plasma, Difco). A positive test was indicated by clumping in 10 seconds.

2 Baker $^{5}$ : A thick suspension of the organism was made in a drop of distilled water. A loopful of pooled human plasma (SNP DADE) was added and a positive result read as the occurrence of immediate clumping.

3 Washington $^{6}$ : As method No 2 with rabbit plasma (Rabbit EDTA plasma, Difco) replacing human plasma.

Methods No 4 and 5 were modifications of the method described for use with Difco Rabbit EDT $A$ plasma. ${ }^{20}$

4 A heavy suspension of the organism was made with minimum spreading in a drop of rabbit plasma (Difco EDTA) on a slide and read for immediate clumping. Reading the results was greatly facilitated by carrying out the procedure with the slide placed on a black tile.

5 This method was similar to method No 4, with human plasma (SNP DADE) replacing rabbit plasma.

In all slide methods that required emulsification in distilled water, if clumping occurred 
Table 1 Efficiency ranking of commercial S aureus identification kits

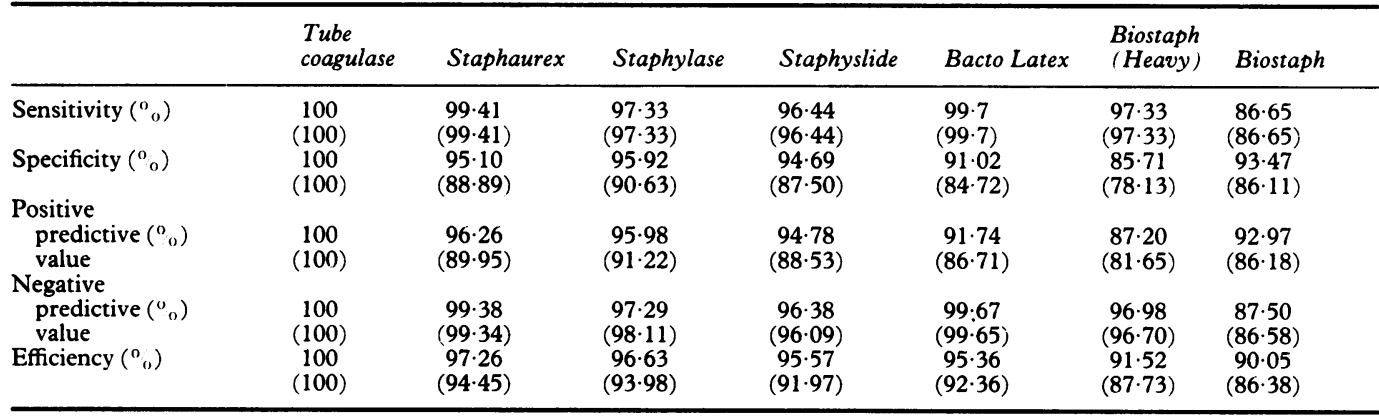

Kits ranked according to efficiency values when testing staphylococcal species alone (number tested $=582$ ). Figures in parentheses are the results when both staphylococcal species and non-staphylococcal species were tested (number tested $=625$ ).

before the addition of plasma the test was deemed "not testable". For methods No 4 and No 5, separate suspensions were made in distilled water to check for non-specific clumping.

All batches of tests were controlled using $S$ aureus NCTC 6571 as a positive control. Tube coagulase tests were also controlled using uninoculated nutrient broth as a negative control.

Evaluation of the slide coagulase test methods was carried out in two parts. All five coagulase methods were used in a pilot study of 365 isolates (220 $S$ aureus, 123 non-S aureus staphylococci and 22 non-staphylococcal species), but only methods No 4 and No 5 were used when testing the remaining isolates.

Results were calculated for sensitivity, specificity, predictive values and efficiency values. Predictive values and efficiency values were calculated according to the method of Galen and Gambino. ${ }^{21}$ Because the ratio of positive to negative results was about $50: 50$ in both test isolates (53.9:46.1) and among our bench coagulase tests during a three month period, which included the time during which the test isolates were collected (49:51), the prevalence of coagulase positive staphylococci was taken to be 50000 per 100000 .

Predictive values and efficiency values have to be calculated with reference to the prevalence of the condition under investigation. Predictive values and efficiency values for a particular test vary for different prevalences, even though the sensitivity and specificity of that test remain the same.

\section{Results}

Table 1 shows the comparison between the reference tube coagulase test and the test kits. The kits are ranked according to their efficiency values. The figures in parentheses show the results when both staphylococcal and non-staphylococcal species are included. Ranked on efficiency, Staphaurex performed best, followed by Staphylase and Staphyslide. Although Bacto Latex showed the highest sensitivity overall, its specificity was lower than any of these three kits. When non-staphylococcal species were included, Staphaurex and Staphylase still scored highest for efficiency but the scores drop from $97 \cdot 26 \%$ to $94.45 \%$ and from $96.63^{\circ}$ o to $93.98^{\circ} \%$, respectively. The mean fall-off in efficiency score resulting from the inclusion of non-staphylococcal species was $3 \cdot 25^{\circ}{ }_{0}$ (range $2 \cdot 65^{\circ}$ o to $3 \cdot 79^{\circ}{ }_{0}$ ), with Staphylase showing the smallest decrease and Biostaph the greatest decrease in efficiency value.

Ranking for efficiency value does not take the proportion of uninterpretable results into account. Table 2 gives the percentage of uninterpretable results with each kit. For GMRSA, only Biostaph gave uninterpretable results: when the test inoculum was increased above the concentration recommended in the manufacturer's instructions, the equivocal isolates gave positive results. Increasing the inoculum, however, resulted in decreased specificity and increased numbers of uninterpretable results with non- $S$ aureus staphylococci and non-staphylococcal species. With non-S aureus staphylococci, Staphylase showed the lowest rate of uninterpretable results, followed by Bacto Latex, and Staphyslide and Staphaurex both with the same rate.

The uninterpretable rate increased for all kits except Bacto Latex with the inclusion of non-staphylococcal species. This increase was most noticeable with Staphyslide and Staphylase. When considering the uninterpretable results, it is important to bear in mind that the Staphylase and Staphyslide kits have control reagents. If the number of control positive tests is subtracted from the uninterpretable tests in

Table 2 Percentage of uninterpretable results

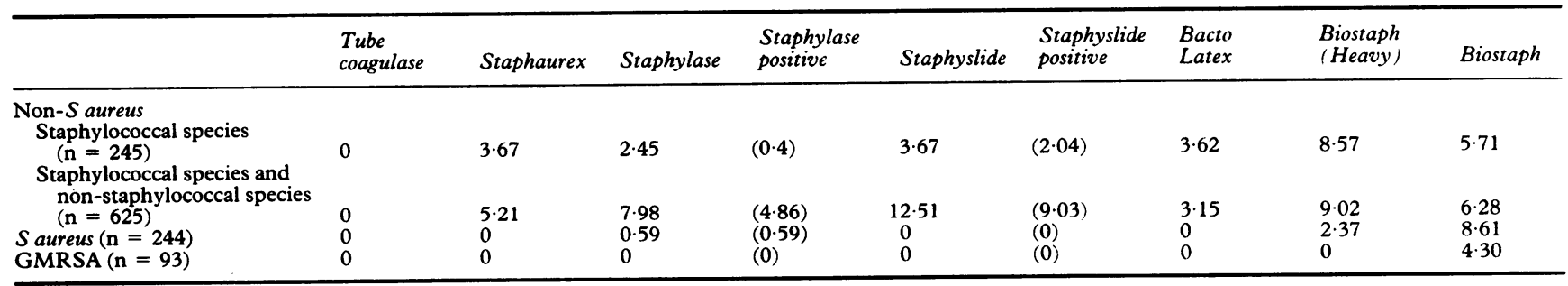


Table 3 Effects on kit performances of storage of isolates and growth on different media

\begin{tabular}{|c|c|c|c|c|c|c|c|c|c|c|c|c|c|}
\hline & \multicolumn{4}{|c|}{ Fresh isolate ( 18 hours at $35 \mathrm{C}$ ) } & \multicolumn{3}{|l|}{24 Hours } & \multicolumn{3}{|l|}{48 Hours } & \multicolumn{3}{|l|}{72 Hours } \\
\hline & $\begin{array}{l}\text { Staphy- } \\
\text { lase }\end{array}$ & $\begin{array}{l}\text { Staph- } \\
\text { aurex }\end{array}$ & $\begin{array}{l}\text { Staphy- } \\
\text { slide }\end{array}$ & $\begin{array}{l}\text { Storage } \\
\text { temperature }\end{array}$ & $\begin{array}{l}\text { Staphy- } \\
\text { lase }\end{array}$ & $\begin{array}{l}\text { Staph- } \\
\text { aurex }\end{array}$ & $\begin{array}{l}\text { Staphy- } \\
\text { slide }\end{array}$ & $\begin{array}{l}\text { Staphy- } \\
\text { lase }\end{array}$ & $\begin{array}{l}\text { Staph- } \\
\text { aurex }\end{array}$ & $\begin{array}{l}\text { Staphy- } \\
\text { slide }\end{array}$ & $\begin{array}{l}\text { Staphy- } \\
\text { lase }\end{array}$ & $\begin{array}{l}\text { Staph- } \\
\text { aurex }\end{array}$ & $\begin{array}{l}\text { Staphy- } \\
\text { slide }\end{array}$ \\
\hline $\begin{array}{l}\text { Blood agar } \\
\text { Blood agar } \\
\text { DST agar } \\
\text { CLED agar } \\
\text { McConkey agar } \\
\text { Mannitol salt agar }\end{array}$ & $\begin{array}{r}0 \\
0 \\
6 \\
11 \\
40 \\
-\end{array}$ & $\begin{array}{r}0 \\
0 \\
7 \\
10 \\
26 \\
-\end{array}$ & $\begin{array}{r}0 \\
0 \\
8 \\
14 \\
32 \\
-\end{array}$ & $\begin{array}{l}\text { Room } \\
\text { temperature } \\
4 \mathrm{C} \\
4 \mathrm{C} \\
4 \mathrm{C} \\
4 \mathrm{C} \\
35 \mathrm{C}\end{array}$ & $\begin{array}{l}0 \\
0 \\
26 \\
9 \\
\mathrm{NT} \\
43\end{array}$ & $\begin{array}{l}3 \\
2 \\
20 \\
13 \\
\mathrm{NT} \\
22\end{array}$ & $\begin{array}{l}0 \\
2 \\
32 \\
14 \\
\text { NT } \\
51\end{array}$ & $\begin{array}{c}1 \\
2 \\
28 \\
8 \\
\text { NT } \\
\text { NT }\end{array}$ & $\begin{array}{c}6 \\
6 \\
27 \\
8 \\
\text { NT } \\
\text { NT }\end{array}$ & $\begin{array}{l}1 \\
5 \\
44 \\
12 \\
\text { NT } \\
\text { NT }\end{array}$ & $\begin{array}{r}6 \\
8 \\
27 \\
16 \\
\text { NT } \\
\text { NT }\end{array}$ & $\begin{array}{l}7 \\
13 \\
23 \\
10 \\
\text { NT } \\
\text { NT }\end{array}$ & $\begin{array}{c}6 \\
13 \\
34 \\
8 \\
\text { NT } \\
\text { NT }\end{array}$ \\
\hline
\end{tabular}

No of isolates (total 121) which were difficult to emulsify or gave equivocal reactions. (NT = not tested).

the staphylococcal group Staphyslide has the lowest overall rate of uninterpretable results followed by Staphylase. The effect of removing the control positive results becomes more noticeable in the combined staphylococcal and non-staphylococcal group, where the kit with the lowest uninterpretable rate becomes Staphylase, followed by Bacto Latex and then Staphyslide. When the uninterpretable rates for Staphylase and Staphyslide are compared, Staphylase gives lower rates of control positive and therefore uninterpretable results in both the staphylococcal and the combined staphylococcal and non-staphylococcal groups, although Staphylase did give a control positive result with one strain of $S$ aureus.

When testing GMRSA (93 isolates), Bacto Latex was the only kit that showed $100^{\circ}{ }_{0}$ sensitivity. The sensitivities of the remaining kits were as follows: Staphaurex $98.92^{\circ}{ }_{0}$, Staphylase $98.92^{\circ}{ }_{0}$, and Biostaph $93.55^{\circ}{ }_{0}$. When the GMRSA isolates were tested with the Biostaph kit using heavy inocula, the sensitivity increased to $97.87^{\circ}{ }_{0}$. The single strain missed by Staphaurex and Staphyslide was negative by all kits except Bacto Latex. This strain, which was methicillin sensitive and gentamicin resistant, seemed to comprise two colony types. On repeat testing, one colony type was positive by Bacto Latex alone while the other colony type was positive by Bacto Latex and Staphaurex (both isolates were tested on three occasions). The same isolate (both strains) was negative by all slide coagulase test methods but positive by both tube coagulase test methods, by DNAse, and by thermonuclease testing.

The effects of storing isolates on Columbia blood agar from 24,48 , and 72 hours at room temperature and at $4 \mathrm{C}$ are shown in table 3 . Also shown are the effects of growth on McConkey agar, DST agar, mannitol salt agar and CLED agar, and of storage on these media for 24,48 , and 72 hours at $4 . \mathrm{C}$.

Storage on Columbia blood agar affected negative rather than positive results, with increasing numbers of negative isolates showing difficulty in emulsifying the test inoculum or giving equivocal results, or both. The effect was more noticeable at $4{ }^{\circ} \mathrm{C}$ and increased with time. Occasionally positive strains reacted more slowly when stored at $4^{\circ} \mathrm{C}$. After 24 and 48 hours of storage at room temperature the greatest number of problem strains occurred with the Staphaurex kit.

Growth on McConkey agar, DST agar, mannitol salt agar or CLED agar increased the number of isolates which were difficult to emulsify among both positive and negative strains. There was also a slower reaction time for a number of positive isolates. These effects were so pronounced on McConkey and mannitol salt agars that no storage evaluation was undertaken with these media. Storage of isolates on DST agar and CLED agar resulted in a pronounced increase in these effects.

During the pilot study of techniques of slide coagulase testing, methods No 1,2 , and 3 showed sensitivities of $40^{\circ}{ }_{0}, 92 \cdot 27^{\circ}{ }_{0}$, and $75^{\circ}{ }_{0}$, with specificities of $81 \cdot 3^{\circ}{ }_{0}, 81 \cdot 3^{\circ}{ }_{0}$, and $86.18^{\circ}$, respectively. The corresponding sensitivities for methods No 4 and 5 were $99.09^{\circ}{ }_{0}$ and $99.08^{\circ} \mathrm{o}$, with specificities of $85 \cdot 37^{\circ}$ o and $84.55^{\circ}{ }_{0}$. The specificities were calculated for two groups of organisms, staphylococcal species alone, and the combined staphylococcal and non-staphylococcal species group. In the latter group the specificities for methods 1 to 5 were $83 \cdot 44^{\circ}{ }_{0}, 80^{\circ}{ }_{0}, 86 \cdot 21^{\circ}{ }^{\circ}$, 86.21 and $84.83^{\circ}$ 。.

Table 4 gives the results of the comparison between the tube coagulase methods and slide methods No 4 (rabbit plasma) and No 5 (human plasma). The methods are ranked

Table 4 Efficiency ranking of two tube coagulase testing methods and two slide coagulase testing methods (Staphylococcal group)

\begin{tabular}{|c|c|c|c|c|}
\hline & $\begin{array}{l}\text { Tube coagulase } \\
\text { reference method }\end{array}$ & $\begin{array}{l}\text { Tube coagulase } \\
\text { St James's Hospital }\end{array}$ & $\begin{array}{l}\text { Slide method } 4 \\
\text { rabbit plasma }\end{array}$ & $\begin{array}{l}\text { Slide method } 5 \\
\text { human plasma }\end{array}$ \\
\hline Sensitivity $\left({ }^{\circ}{ }_{0}\right)$ & 100 & $99 \cdot 70$ & 97.92 & $97 \cdot 33$ \\
\hline & $(100)$ & $(99 \cdot 70)$ & $(97.92)$ & $(97.33)$ \\
\hline Specincity $\left({ }_{0}\right)$ & $\begin{array}{l}100 \\
(100)\end{array}$ & $\begin{array}{c}100 \\
(100)\end{array}$ & $\begin{array}{c}90 \cdot 61 \\
(89.58)\end{array}$ & $\begin{array}{r}88.98 \\
(88.89\end{array}$ \\
\hline \multicolumn{5}{|l|}{ Positive } \\
\hline $\begin{array}{l}\text { predictive }\left({ }^{\prime \prime}{ }_{11}\right) \\
\text { value }\end{array}$ & 100 & 100 & $91 \cdot 25$ & $89 \cdot 83$ \\
\hline \multicolumn{5}{|l|}{ Negative } \\
\hline $\begin{array}{l}\text { predictive }\left({ }^{0}{ }_{0}\right) \\
\text { value }\end{array}$ & 100 & $\begin{array}{c}99 \cdot 70 \\
99.70\end{array}$ & 97.76 & 97.09 \\
\hline Efficiency $\left({ }^{\circ}{ }_{0}\right)$ & $\begin{array}{l}(100) \\
100\end{array}$ & $\begin{array}{l}(99 \cdot 70) \\
99 \cdot 85\end{array}$ & $\begin{array}{l}(97 \cdot 73) \\
94 \cdot 27\end{array}$ & $\begin{array}{l}(97 \cdot 08) \\
93 \cdot 16\end{array}$ \\
\hline & (100) & $(99.85)$ & $(93.75)$ & $(93 \cdot 11)$ \\
\hline
\end{tabular}

Figures in parentheses are the results when the non-staphylococcus species group are included. 
Table 5 Efficiency ranking of two tube coagulase test methods, two slide coagulase test methods, and five $S$ aureus identification kits (Staphylococcal and non-staphylococcal group)

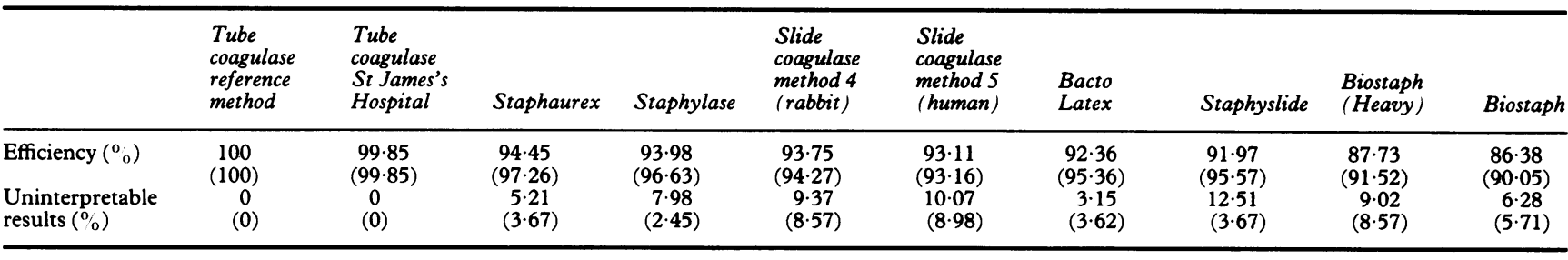

Figures in parentheses are the results with the staphylococcal group only.

according to their efficiency values. Results when the non-staphylococcal species are included are shown in parentheses.

The percentage of uninterpretable results (autoagglutinable or equivocal $( \pm)$ reactions) for both slide coagulase methods is high, when testing non-S aureus staphylococci $(8.57 \%$ for method No 4 and $8.98 \%$ for method No 5 ). When the non-staphylococcal species are included, the uninterpretable rate rises to $9.37 \%$ for method No 4 and $10.07 \%$ for method No 5. There were no uninterpretable results when $S$ aureus (including GMRSA) were tested by either slide coagulase method.

The St James's Hospital tube coagulase test method compares well with the reference method, showing $100 \%$ specificity and $99.7 \%$ sensitivity. The evaluation of the five slide coagulase test methods shows methods No 4 and No 5 to be superior to methods No 1,2 , or 3 , with method No 4 (rabbit plasma) performing slightly better than method No 5 (human plasma). Methods No 4 and 5 showed sensitivities of $97.92 \%$ and $97.33 \%$, respectively. Unfortunately both methods have unacceptably low specificities $(90.61 \%$ and $88.98 \%)$ and high rates of uninterpretable results.

\section{Discussion}

The accepted basis of $S$ aureus identification is coagulase testing. Staphylocoagulase production in vitro has been shown to be affected by many factors ${ }^{22}$ and tube coagulase test results vary depending on the methods used (type $\mathrm{e}^{1-3}$ ) or $\operatorname{lot}^{23}$ of plasma, type of anticoagulant ${ }^{1-3}$, period of incubation ${ }^{3}$ etc). Other problems with tube coagulase testing include the production of coagulase by non-staphylococcal speciesfor example, Pseudomonas aeruginosa and Serratia marcescens, ${ }^{2}$ by non- $S$ aureus staphylococci-for example $S$ hyicus and $S$ intermedius, ${ }^{24}$ the production of pseudocoagulase $^{3}$ and the time required to produce a final result. The SJH method provides a final result within 24 hours, is simpler to perform, and compared well with the reference method.

Despite its problems tube coagulase testing is the accepted basis of $S$ aureus identification, with rapid results being provided by slide coagulase testing. There are numerous modifications of methods of tube and slide coagulase testing, ${ }^{25}$ and rates of false negative results with the slide coagulase test varying from $3 \%$ to $15 \%$ are quoted. ${ }^{13}$ Using slide coagulase test methods No 4 and 5, the false negative rate can be brought down to $2.08 \%$ and $2.67 \%$, respectively. The problems of low specificity and high uninterpretable rates remain. The numerous modifications of coagulase testing used in evaluations of commercial $S$ aureus identification kits make it difficult to assess comparative performances from the literature..$^{9101214-16}$

In this evaluation the kits that performed best were Staphaurex and Staphylase with sensitivities of $99.41 \%$ and $97.33 \%$ and specificities of $95.10 \%$ and $95.92 \%$, respectively, with the staphylococcal group of isolates. In the routine diagnostic laboratory the results that have to be considered are those of the combined staphylococcal and nonstaphylococcal group. Here, the specificities drop to $88.89 \%$ and $90.63 \%$ with $5.21 \%$ and $7.98 \%$ of results uninterpretable. These specificities and uninterpretable rates are unacceptable for the routine identification of $S$ aureus.

While it can be argued that all isolates should be staphylococci, the proportion of nonstaphylococcal species tested was chosen to represent the bench situation. Most kit instructions and good bacteriological techniques dictate that only catalase positive, Gram positive cocci be selected as presumptive staphylococcal species. To recommend routine catalase testing and Gram staining of all presumptive staphylocci in a large busy routine microbiology department, however, is an impractical counsel of perfection. Because, on occasion, non-staphylococcal species may be inadequately tested in the routine diagnostic laboratory, it is important to know how the kits perform with non-staphylococcal species so that the reliability of results can be assessed.

The effects of non-staphylococcal species on the kits' performances are to increase the numbers of false positive and uninterpretable

Table 6 Comparison of modified Biostaph kit with Staphaurex

\begin{tabular}{|c|c|c|c|c|}
\hline & \multirow[b]{2}{*}{ Staphaurex } & \multirow[b]{2}{*}{ Modified Biostaph } & \multicolumn{2}{|c|}{ From main study } \\
\hline & & & Biostaph & Biostaph (Heavy) \\
\hline $\begin{array}{l}\text { Sensitivity }{ }^{\circ} \\
\text { Specificity }{ }^{\star} \\
\text { Specificity }{ }^{\circ} \%\end{array}$ & $\begin{array}{r}100 \cdot 0 \\
92 \cdot 7 \\
91 \cdot 3\end{array}$ & $\begin{array}{l}98 \cdot 4 \\
85 \cdot 4 \\
76 \cdot 1\end{array}$ & $\begin{array}{l}86 \cdot 65 \\
93 \cdot 47 \\
86 \cdot 11\end{array}$ & $\begin{array}{l}97 \cdot 33 \\
85 \cdot 71 \\
78 \cdot 13 \\
\end{array}$ \\
\hline
\end{tabular}

«Staphylococcal species alone.

+Staphylococcal species and non-staphylococcal species. 
results. As the kits are marketed as systems for the rapid identification of $S$ aureus, the issuing of rapid positive results from primary plates would have to be viewed with caution. While Gram staining and catalase testing will confirm the presence of staphylococci, the presence of unsuspected mixtures may give rise to false positive results.

When identifying $S$ aureus by latex or haemagglutination kits a minimum inoculum density is critical. If the inoculum is too small $S$ aureus isolates may give negative results. To pick four to five identical colonies from a plate that may contain perhaps three different types of staphylococci presents a problem. There may also be insufficient inoculum available because only one or two colonies have grown on the primary plate or the colonies have not grown to the "average-sized colonies" which is the required inoculum specified in the manufacturer's instructions. When more than one strain of Staphylococcus species is present, the colonies subcultured for sensitivity testing may not be the isolates giving positive kit results.

Staphylococci from urine specimens were not included in this evaluation, partly to avoid too many negative results. A problem reported in kit testing of urinary isolates of staphylococci is that $S$ saprophyticus may give false positive results. ${ }^{11132627}$ Therefore all positive results on isolates from urine specimens would have to be confirmed by another method.

The reported problem of kits having difficulty identifying GMRSA does not seem to pose a major problem with our GMRSA population. ${ }^{1114162829}$ Only one GMRSA isolate gave negative kit results. This isolate, mentioned earlier, seemed to comprise two strains, one of which was positive by Staphaurex. It may perhaps be inaccurate to assign a sensitivity of $98.92^{\circ}{ }_{0}$ rather than $100^{\circ}{ }_{0}$ to Staphaurex when testing GMRSA.

The effects of different media on the kits' performances are such that none of the media tested other than Columbia blood agar can be recommended for use with these kits. This poses a problem with, for example, urine specimens, where isolates may be available only on CLED agar or McConkey agar. Similarly, storage for 48 hours or longer at either room temperature or $4^{\circ} \mathrm{C}$ is not an option. Storage for even 24 hours at room temperature is problematic. The difficulty here is dealing with isolates stored at $4{ }^{\circ} \mathrm{C}$ over the weekend.

An objective of introducing a kit at the stage of reading primary plates would be to cut down on time and material by eliminating unnecessary sensitivity testing of non- $S$ aureus staphylococci. Sensitivity tests, however, are needed on all staphylococcal isolates from certain specimens-for example, blood cultures, peritoneal dialysis fluids, and specimens from oncology patients. There are also occasions when sensitivities need to be available though they may not necessarily be reported for example, possible contaminants from normally sterile sites such as pleural fluids, joint fluids etc.

Another objective of introducing a kit at primary plate reading stage is to provide rapid results. Blood cultures, sputa, and cerebrospinal fluid specimens need rapid results. The number of staphylococcal isolates from sputa and cerebrospinal fluid specimens is small. By performing the SJH modification of the tube coagulase test on the broth medium in a Bactec bottle that gives a positive growth index and shows Gram positive cocci in a Gram stained smear, the tube coagulase test result is usually available at the same time as the first subculture plates.

For those occasions when a rapid result is required, perhaps the limited use of a kit might be considered with emphasis on the need to Gram stain and catalase test all positive isolates. It does not, however, seem that the general introduction of a kit system to replace tube coagulase testing at the stage of reading primary plates is to be recommended.

It is often unclear from published reports whether commercial $S$ aureus identification kits are intended to replace slide coagulase testing or tube coagulase testing. ${ }^{7-1114262730}$ Table 5 compares the results obtained with the five commercial kits evaluated, two tube coagulase testing methods, and two slide coagulase testing methods. Ranked according to their efficiency values for the combined staphylococcal and non-staphylococcal species group, the two slide coagulase test methods rank just below the two commercial kits that performed best in the kit evaluation. Both slide coagulase test methods, however, show a greater percentage of uninterpretable results than either of these two kits.

If it is accepted that negative slide coagulase tests must be checked by tube coagulase testing, this comparison indicates that negative kit results should also be checked by tube coagulase testing. In this case commercial $S$ aureus identification kits do not provide rapid negative results and have little advantage over slide coagulase testing, except perhaps to provide rapid results when isolates of $S$ aureus produce uninterpretable results in the slide coagulase test.

Since this evaluation was performed, the Biostaph kit has been modified. This modified kit was briefly examined using 107 recent clinical isolates. Staphylococci were identified as $S$ aureus or non- $S$ aureus staphylococci by the reference tube coagulase test. The test isolates consisted of $61 S$ aureus (including 17 GMRSA), 41 non- $S$ aureus staphylococci, and five non-staphylococcal isolates.

The results of a comparison of this kit with Staphaurex are shown in table 6 . The results of the original Biostaph kit from the main study are included for comparison. The modified Biostaph kit shows results comparable with the effect of increasing the test inoculum with the original kit-that is, an increase in sensitivity and a decrease in specificity.

We gratefully acknowledge the cooperation of the technical staff of the Microbiology Department, St James's Hospital, in collecting isolates and we thank Ms J Bite for typing the manuscript. We thank BM Browne Limited for the gift of Oxoid Staphylase kits and acknowledge the evaluation facility afforded by the following companies: Novopath (Difco, Bacto Latex kits), Medical Supply Company (bioMèrieux, Staphyslide), Medlabs (Biostaph), and Wellcome (Ireland) Limited (Staphaurex). 
1 Buchanan RE, Gibbons NE, eds. Bergey's manual of determinative bacteriology. 8th ed. Baltimore: The Williams and Williams Company, 1974:486.

2 Parker MT, ed. Topley and Wilson's principles of bacteriology, virology and immunity. Volume 2. 7 th ed. London: Edward Arnold, 1983:225-9.

3 Jeljaszewiczj J, Switalski LM, Adlam C. Staphylocoagulase and clumping factor. In: Easmon CSF, Adlam C, eds. and clumping factor. In: Easmon CSF, Adlam C, eds. Staphylococci and staphylococcal infec

4 Cowan ST, Steel KG. Manual for the identification of medical bacteria. 2nd ed. Cambridge: Cambridge University Press, 1974:171-2.

5 Baker FJ, Breach MR. Medical microbiological techniques. London: Butterworths, 1980:94.

6 Washington JA, ed. Laboratory procedures in clinical microbiology. New York: Springer-Verlag, 1980:137-8.

7 Flandrois JP, Carret G. Study of the staphylococcal affinity to fibrinogen by passive haemagglutination: a tool for the Staphylococcus aureus identification. Zbl Bakt $\mathrm{Hyg} 1 \mathrm{Abt}$ Orig $A$ 1981;251:171-6.

8 Essers L, Radebold K. Rapid and reliable identification of Staphylococcus aureus by a latex agglutination test. $J$ Clin Microbiol 1980;12:641-3.

9 Jungkind DL, Torhan NJ, Corman KE, Bondi JM. Comparison of two commercially available test methods with conventional coagulase tests for identification of Staphylococcus aureus. J Clin Microbiol 1984;19:191-3.

10 Baker JS, Borman MA, Boudreau DH. Evaluation of various rapid agglutination methods for the identification of Staphylococcus aureus. J Clin Microbiol 1985;21:726-9.

11 Berke A, Tilton RC. Evaluation of rapid coagulase methods for the identification of Staphylococcus aureus. J Clin Microbiol 1986;23:916-9.

12 Punsalang A, Migneault PC, Nolte FS. Reliability of latex agglutination tests for identification of Staphylococcus aureus resistant to oxacillin. J Clin Microbiol 1986; 24:1104-6.

13 Mifsud AJ, Parker SC. Staphaurex reappraised: role of protein $\mathrm{A}$ in false positive results and recommendation for use. J Clin Pathol 1987;40:808-12.

14 Dickson JIS, Marples RR. Coagulase production by strain of Staphylococcus aureus of different resistance characters: a comparison of two traditional methods with a latex agglutination system detecting both clumping factor and protein A J Clin Pathol 1986;39:371-5.

15 Weers-Pothoff G, Moolhuizzen CEM, Bongaerts GPA Comparison of seven coagulase tests for identification of
Staphylococcus aureus. Eur J Clin Microbiol 1987;6: 589-91.

16 Cremer AW, Gruneberg RN. Assessment of a new test 'Staphylase' for the identification of Staphylococcus aureus. Med Lab Sci 1988:45:221-4.

17 Jacobs SI, Willis AT, Goodburn GM. Pigment production and enzymic activity of staphylococci: the differentiation of pathogens from commensals. J Pathol Bacteriol of pathogens
$1964 ; 87: 151-6$.

18 Lachica RUF, Genigeorgis C, Hoeprich PD. Metachromatic agar-diffusion methods for detecting staphylococcal nuclease activity. Appl Microbiol 1971;21:585-7.

19 Oxoid Limited. The Oxoid manual. 5th ed. 1982:187-8.

20 Difco. Bactocoagulase Plasma. Bactocoagulase Plasma EDT A. Difco Laboratories, 1985:1.

21 Galen RS, Gambino SR. Beyond normality: the predictive value and efficiency of medical diagnoses. New York: John Wiley and Sons 1975:30-3.

22 Davies GE. Factors influencing the in vitro production of staphylococcal coagulase. J Gen Microbiol 1951;5:687-97.

23 Selepak ST, Witebsky FG. Inoculum size and lot-to-lo variation as significant variables in the tube coagulase test for Staphylococcus aureus. J Clin Microbiol 1985;22 835-7.

24 Phillips WE, Kloos WE. Identification of coagulase-positive Staphylococcus intermedius and Staphylococcus hyicus ubsp. hyicus isolates from veterinary clinical specimens. $J$ Clin Microbiol 1981;14:671-3.

25 Tager M, Drummond MC. Staphylocoagulase. Ann NY Acad Sci 1965;128:92-111.

26 Gregson DB, Low DE, Skulnick M, Simor AE. Problems with rapid agglutination methods for identification of Staphylococcus aureus when Staphylococcus saproStaphylococcus aureus when Staphylococcus sapro-

27 Aldridge KE, Kogas C, Sanders CV, Marier RL. Comparison of rapid identification assays for Staphylococcu aureus. J Clin Microbiol 1984;19:703-4.

28 Ruane PJ, Morgan MA, Citron DM, Mulligan ME. Failure of rapid agglutination methods to detect oxacillin resistan Staphylococcus aureus. J Clin Microbiol 1986;24:490-2.

29 Piper J, Hadfield T, McCleskey F, et al. Efficacies of rapid agglutination tests for identification of methicillinresistant staphylococcal strains as Staphylococcus aureus. J Clin Microbiol 1988;26:1907-9.

30 Coles M, Brown DFJ "Staphaurex" negative, methicillin resistant Staphylococcus aureus. J Clin Pathol 1986;39:1365. 